\title{
Effect of hospitalization on the nutritional status of the Mexican elderly
}

\author{
Brenda D. Avilán-Salas ${ }^{1}$, Sandra M. González-Peña ${ }^{1}$, Homero Nañes-Terreros², Paula Cordero-Pérez ${ }^{3}$, \\ Cecilia H. Albala-Brevis', and Patricia R. Ancer-Rodríguez ${ }^{1 *}$ \\ ${ }^{1}$ Outpatint Clinic 2 Nutrition, "Dr. José Eleuterio González" University Hospital, Universidad Autonoma de Nuevo León, Nuevo Leon, Mexico; \\ ${ }^{2}$ Department of Internal Medicine, "Dr. José Eleuterio González" University Hospital, Universidad Autonoma de Nuevo León, Nuevo Leon, Mexico; \\ ${ }^{3}$ Liver Unit,"'Dr. José Eleuterio González" University Hospital, Universidad Autonoma de Nuevo León, Nuevo Leon, Mexico; "Institute of Nutrition \\ and Food Technology, Universidad de Chile, Chile
}

\begin{abstract}
Objective: The objective of the study was to determine the prevalence of malnutrition and risk of malnutrition and evaluate the effects of hospitalization on nutritional status and muscle mass in the elderly. Methods: Older adults ( $\geq 60$ years) were recruited at the Internal Medicine area of the "Dr. José Eleuterio González" University Hospital. Calf circumference (cerebral palsy [CP]) and muscle function through handgrip strength measured by dynamometry were determined on admission and discharge, and baseline nutritional status was determined by the Mini Nutritional Assessment Short-Form (MNA-SF). Statistical analyses were made in STATA v.13 $(p<0.05)$. Results: One hundred and twelve patients $(57 \%$ men) were evaluated, with a mean age of $71.56 \pm 8.5$ years, and an average hospital stay of $5.95 \pm 4.6$ days. Fifteen (13\%) deaths were reported during VCA Hospital stay. According to the score obtained in the MNA-SF, 38.4\% of the subjects presented malnutrition upon admission; a higher prevalence of malnutrition was found in patients diagnosed with cancer (75\%) followed by those with genitourinary (59\%) and respiratory problems (38\%); in CP, 54\% of those admitted showed low muscle mass $(<31 \mathrm{~cm})$; there was also low muscular strength in the dynamometry, with a higher prevalence in women $(81 \% \leq 15 \mathrm{~kg})$ than in men $(73 \% \leq 27 \mathrm{~kg})$. Conclusions: Hospitalization of the elderly is a negative factor not only for the risk of malnutrition but also for their muscle mass and strength, both at admission and progress; therefore, an adequate assessment of nutritional status at hospital admission is essential.
\end{abstract}

Key words: Nutrition. Elderly. Hospitalization.

\section{Introduction}

Natural aging is a phenomenon present throughout the cycle of life, from conception up until death. It is considered a challenge for public health domestically as well as internationally since the switch in the population pyramid has turned toward a rise in this population ${ }^{1}$. This growth is also sample of the increase in life expectancy, which in Mexico was 75.5 years in 2018 for the general population, with the state of Nuevo Leon having the highest life expectancy, with 79.2 years for women and 75 years for men².

Elderly people present physiological changes with a progressive decline in organic and psychological functions, in addition to a loss of sensory and cognitive capabilities ${ }^{1}$. Different prognostic factors such as nutritional status, malnutrition, and involuntary weight loss

\section{Correspondence:}

*Patricia R. Ancer Rodríguez

E-mail: patyaner@hotmail.com
Date of reception: 06-08-2019

DOI: 10.24875/RMU.20000117
Available online: 18-06-2020
Medicina Universitaria. 2020;22(2):54-60
www.medicinauniversitaria.org www.medicinauniversitaria.org (http://creativecommons.org/licenses/by-nc-nd/4.0/) 
during this stage of life have been reported to contribute to a progressive decline in physical and cognitive status, as well as in health ${ }^{3}$. Hospital malnutrition in the elderly is a problem which leads to an increase in delirium, immobility, functional decline, nutritional problems, falls, gait and balance disorders, urinary incontinence, constipation, polypharmacy, and pressure ulcerations $^{4-6}$. This is linked to different factors such as an inadequate administration of food services, lack of trained personnel for the detection, diagnosis and treatment of malnutrition, unawareness of useful tools for early diagnosis, frequent and prolonged fasting periods, and late nutritional support with a catabolic nutritional status ${ }^{7,8}$.

Having stated this, the older adult who is hospitalized with malnutrition develops higher rates of morbidity and mortality, thus increasing the amount of days in their stay and the cost to health systems ${ }^{9}$. Therefore, a systemic nutritional test is recommended, structured for early detection of malnutrition and to optimize health care. The nutritional scale Mini Nutritional Assessment (MNA) is widely validated as a screening method for early detection of hospital malnutrition in the elderly. A short version of the test is available: the MNA ShortForm (MNA-SF) developed and validated in 2001 by Rubenstein et al. who incorporates a cutoff point for malnutrition ${ }^{10,11}$.

At present, in Mexico, no studies on the prevalence of malnutrition and/or risk of malnutrition in elderly patients hospitalized in third-level care units using MNASF have been reported. Accordingly, the objective of this study was to determine the prevalence of malnutrition and risk of malnutrition, as well as to evaluate the effect of hospitalization on the nutritional status and muscle mass of the elderly.

\section{Methods}

A descriptive, observational study was conducted in older adults ( $\geq 60$ years), both male and female, who were admitted at the Department of Internal Medicine of the "Dr. José Eleuterio González" University Hospital, in Monterrey, Nuevo Leon, Mexico, between April and July 2017.

The sample size was determined using the Miller method $^{12}$, at a Level-III inspection, obtaining a minimum of $n=50$; however, a final sample of 112 older adults was obtained (48 females and 64 males). An anthropometric evaluation was conducted on admission and discharge, including calf circumference $(<31 \mathrm{~cm}$ was classified as reduced muscle mass for both genders) $)^{13}$, muscle function through handgrip strength measured by dynamometry with a cutoff point of $\leq 15 \mathrm{~kg}$ in women and $\leq 27$ in men ${ }^{14}$; baseline nutritional status was determined by the MNA-SF, which consists of six sections: (1) have you eaten less than usual due to a lack of appetite in the past 3 months?, (2) have you lost any weight in the past 3 months?, (3) mobility, (4) disease or psychological stress in the past 3 months, (5) neuropsychological problems, and (6) calf circumference since we did not have their body mass index (BMI). The total possible score is 14 points and allows for the classification of assessed people into three groups: 12-14 points, a normal nutritional status, 8-11, risk of malnutrition, and $0-7$, malnutrition ${ }^{15}$. The cause of hospitalization was recorded according to the International Classification of Diseases 10 (CIE10) ${ }^{16}$.

Data recollection was performed using Microsoft Excel 2007, and statistical analyses were conducted in STATA v.13. Descriptive statistics were obtained (average, standard deviation for quantitative variables, and frequency for qualitative variables).

For the comparison of variables, the Chi-square test for discretion and the Pearson correlation test were conducted to evaluate the correlation between MNA-SF and muscle strength. Values of $p<0.05$ were considered significant.

This research protocol was evaluated and approved by the Ethics Research Committee at the "Dr. Jose Eleuterio Gonzalez" University Hospital, with the registry EN17-00005.

\section{Results}

A total of 112 patients were evaluated from patients who were admitted to the "Dr. Jose Eleuterio Gonzalez" University Hospital in Monterrey. This is a third-level hospital, which works alongside popular insurance to support people of a medium-low and low socioeconomic class.

Table 1 presents the general characteristics of the studied population on their admittance to the hospital.

Regarding the assessment of the nutritional status of elderly patients according to the MNA-SF on hospital admittance, there were only two sections where a significant difference was observed: "have you eaten less due to the lack of appetite, digestive problems, or difficulty chewing or swallowing in the past 3 months?" ( $p=0.014)$ and "mobility" ( $p=0.002)$ (Table 2).

The causes of hospitalization of the elderly are described in table 3; there was only one significant difference regarding gender with diseases of the genitourinary 
Table 1. General characteristics of the population upon admission to the “Dr. José Eleuterio González" University Hospital

\begin{tabular}{|c|c|c|c|}
\hline & General population $n=112$ (media \pm SD) & Men $n=64$ (media \pm SD) & Women $n=48$ (media \pm SD) \\
\hline Age (years) & $71.56 \pm 8.5$ & $70.52 \pm 7.7$ & $72.96 \pm 9.3$ \\
\hline Hospital stay (days) & $5.95 \pm 4.6$ & $5.6 \pm 4.2$ & $6.4 \pm 5.1$ \\
\hline Calf circumference $(\mathrm{cm})$ & $30.5 \pm 4.3$ & $30.8 \pm 4.3$ & $30.1 \pm 4.3$ \\
\hline Strength $(\mathrm{kg})$ & $14.99 \pm 10.7$ & $20.1 \pm 10.2$ & $8.2 \pm 7.0$ \\
\hline
\end{tabular}

SD: standard deviation.

Table 2. Diagnostic categories of the nutritional state of the MNA-SF for a hospitalized elder

\begin{tabular}{|c|c|c|c|c|}
\hline Diagnostic categories & General population ( $=112)$ n (\%) & Men $(n=64) n(\%)$ & Women ( $=48)$ n (\%) & $\mathbf{p}^{1}$ \\
\hline \multicolumn{5}{|c|}{ Have you eaten less due to a lack of appetite, digestive problems, or difficulties chewing or swallowing in the past 3 months? } \\
\hline $\begin{array}{l}\text { Eaten much less } \\
\text { Eaten less } \\
\text { Eaten the same }\end{array}$ & $\begin{array}{l}22(19.6) \\
41(36.6) \\
49(43.7)\end{array}$ & $\begin{array}{l}8(12.5) \\
21(32.8) \\
35(54.6)\end{array}$ & $\begin{array}{l}14(29.1) \\
20(41.6) \\
14(29.1)\end{array}$ & $0.014^{*}$ \\
\hline $\begin{array}{l}\text { Weight loss } \\
\text { Weight loss > } 3 \mathrm{~kg} \\
\text { Do not know } \\
\text { Weight loss between } 1 \text { and } 3 \mathrm{~kg} \\
\text { No weight loss }\end{array}$ & $\begin{array}{c}38(33.9) \\
9(8.0) \\
24(21.4) \\
41(36.6)\end{array}$ & $\begin{aligned} 22 & (34.3) \\
5 & (7.8) \\
10 & (15.6) \\
27 & (42.1)\end{aligned}$ & $\begin{aligned} 16 & (33.3) \\
4 & (8.3) \\
14 & (29.1) \\
14 & (29.1)\end{aligned}$ & 0.304 \\
\hline $\begin{array}{l}\text { Mobility } \\
\text { From the bed to the couch } \\
\text { Autonomy inside } \\
\text { Leave the house }\end{array}$ & $\begin{array}{l}17(15.1) \\
25(22.3) \\
70(62.5)\end{array}$ & $\begin{array}{c}3(4.6) \\
16(25) \\
45(70.3)\end{array}$ & $\begin{array}{c}14(29.1) \\
9(18.7) \\
25(52.0)\end{array}$ & $0.002^{*}$ \\
\hline $\begin{array}{l}\text { Acute illness } \\
\text { Yes } \\
\text { No }\end{array}$ & $\begin{array}{l}58(51.7) \\
54(48.2)\end{array}$ & $\begin{array}{l}34(53.1) \\
30(46.8)\end{array}$ & $\begin{array}{l}24(50) \\
24(50)\end{array}$ & 0.743 \\
\hline $\begin{array}{l}\text { Neuropsychological problems } \\
\text { Dementia or severe depression } \\
\text { Moderate dementia } \\
\text { No psychological problems }\end{array}$ & $\begin{array}{c}2(1.7) \\
33(29.4) \\
77(68.7)\end{array}$ & $\begin{array}{c}0 \\
17(26.5) \\
47(73.4)\end{array}$ & $\begin{array}{c}2(4.1) \\
16(33.3) \\
30(62.5)\end{array}$ & 0.168 \\
\hline $\begin{array}{l}\text { Calf } \\
\qquad 31 \\
\geq 31\end{array}$ & $\begin{array}{l}61(54.4) \\
51(46.5)\end{array}$ & $\begin{array}{l}33(51.5) \\
31(48.4)\end{array}$ & $\begin{array}{l}28(58.3) \\
20(41.6)\end{array}$ & 0.583 \\
\hline $\begin{array}{l}\text { MNA-SF } \\
\text { Normal } \\
\text { Malnutrition risk } \\
\text { Malnutrition }\end{array}$ & $\begin{array}{c}20(17.8) \\
49(43.7) \\
43(38.3)\end{array}$ & $\begin{array}{l}14(21.8) \\
28(43.7) \\
22(34.3)\end{array}$ & $\begin{array}{c}6(12.5) \\
21(43.7) \\
21(43.7)\end{array}$ & 0.372 \\
\hline
\end{tabular}

${ }^{1}$ Chi-square.

*Difference between the categories analyzed in men and women $(\mathrm{p}<0.05)$. MNA-SF: Mini Nutritional Assessment Short-Form.

system, which showed a greater frequency among women $(64.7 \%$ vs. $35.5 \%, p=0.048)$.

Moreover, the relation between MNA-SF results and the cause of hospitalization was determined (Table 3), observing that the higher prevalence of malnutrition in patients on hospital admittance was in patients with a cancer diagnosis $(75 \%)$ followed by those with problems in the genitourinary system (59\%) and respiratory system (38\%). In the case of the circulatory system and malignant tumors, a significant difference was observed concerning nutritional status, with $54 \%$ showing a risk of malnutrition ( $p=0.014$ ) and $75 \%$ with malnutrition ( $p=0.005)$.

In the strength test, $77 \%$ of elderly adults presented a decrease in muscle strength, with a higher prevalence in female $(81 \% \leq 15 \mathrm{~kg})$ than male $(73 \% \leq 27 \mathrm{~kg})$, 
Table 3. Causes of hospitalization according to MNA-SF in patients over 60

\begin{tabular}{|l|c|c|c|c|}
\hline Cause of hospitalization & Malnutrition $\mathbf{n}(\%)$ & Malnutrition risk $\mathbf{n}(\%)$ & Normal $\mathbf{n}(\%)$ & $\mathbf{p}^{\mathbf{1}}$ \\
\hline Circulatory system & $6(18)$ & $18(54)$ & $9(27)$ & $0.014^{*}$ \\
\hline Malignant tumors & $12(75)$ & $3(19)$ & $1(12)$ & $0.005^{*}$ \\
\hline Respiratory system & $3(38)$ & $4(50)$ & $7(26)$ & 0.897 \\
\hline Digestive system & $8(30)$ & $12(44)$ & $1(6)$ & 0.366 \\
\hline Genitourinary system & $10(59)$ & $6(35)$ & $1(9)$ & 0.128 \\
\hline Other & $4(36)$ & $6(55)$ & 0.650 \\
\hline
\end{tabular}

${ }^{1}$ Chi-square.

*Difference between the categories analyzed in men and women $(p<0.05)$.

MNA-SF: Mini Nutritional Assessment Short-Form.

Table 4. Evolution of calf circumference in the hospitalization of the elderly

\begin{tabular}{|c|c|c|c|c|c|c|}
\hline \multirow[t]{3}{*}{ Admission (cm) } & \multicolumn{4}{|c|}{ Discharge } & \multirow[t]{3}{*}{ Total n (\%) } & \multirow[t]{3}{*}{$p^{1}$} \\
\hline & \multicolumn{2}{|c|}{ Alive } & \multicolumn{2}{|c|}{ Dead } & & \\
\hline & $<31 \mathrm{n}(\%)$ & $\geq 31$ n (\%) & $<31 \mathrm{n}(\%)$ & $\geq 31$ n (\%) & & \\
\hline$<31$ & 50 (81.9) & $3(4.9)$ & $4(6.5)$ & $1(1.6)$ & $61(100)$ & $0.001 *$ \\
\hline$\geq 31$ & $5(9.8)$ & $39(76.4)$ & $1(1.9)$ & $5(9.8)$ & $51(100)$ & \\
\hline Total & $55(49.1)$ & $42(37.5)$ & $5(4.4)$ & $6(5.3)$ & $112(100)$ & \\
\hline
\end{tabular}

${ }^{1}$ Chi-square.

*Difference between the categories analyzed in men and women $(p<0.05)$.

Table 5. Trajectory of nutritional state at admission of the elderly, according to nutritional status at discharge in the period April 2017-July 2017

\begin{tabular}{|l|c|}
\hline Admission n (\%) & Discharge n (\%) \\
\hline Malnutrition $43(38.3)$ & \\
Malnutrition & $25(58)$ \\
Malnutrition risk & $9(21)$ \\
Normal & 0 \\
Death & $9(21)$ \\
\hline Malnutrition risk 49 (43.7) & \\
Malnutrition & $12(24)$ \\
Malnutrition risk & $24(49)$ \\
Normal & $7(14)$ \\
Death & $6(12)$ \\
\hline Normal 20 (17.8) & \\
Malnutrition & 0 \\
Malnutrition risk & $9(45)$ \\
Normal & $11(55)$ \\
Death & 0 \\
\hline
\end{tabular}

and only $23 \%$ of the total displayed a normal strength; however, there was no significant difference between genders $(p=0.716)$ (Fig. 1), while with muscle strength and nutritional status according to MNA-SF, a positive correlation was observed with handgrip strength $(r=0.50, p \leq 0.001)$ (Fig. 2).

In table 4 , the evolution of calf circumference is described on admittance compared to hospital discharge. Sixty-one patients scored a circumference $<31 \mathrm{~cm}$ during hospitalization, noting that in 50 patients $(81.9 \%)$, it remained the same at their discharge and $8 \%(13.1 \%)$ died, observing a statistically significant difference ( $p \leq 0.001)$.

During the study, a total of 15 patients died (seven women and eight men), without a difference regarding calf circumference on admittance.

Table 5 describes the distribution of MNA-SF during hospitalization and the trajectory toward discharge according to the nutritional state. Forty-three patients (38.3\%) presented malnutrition when admitted, 58\% remained in malnutrition, and $21 \%$ died during hospitalization. Out of the 49 patients $(43.7 \%)$ with a risk of malnutrition upon admittance, $49 \%$ continued with the risk, $24 \%$ presented malnutrition upon discharge, and $12 \%$ died; concerning the 20 patients (17.8\%) who 


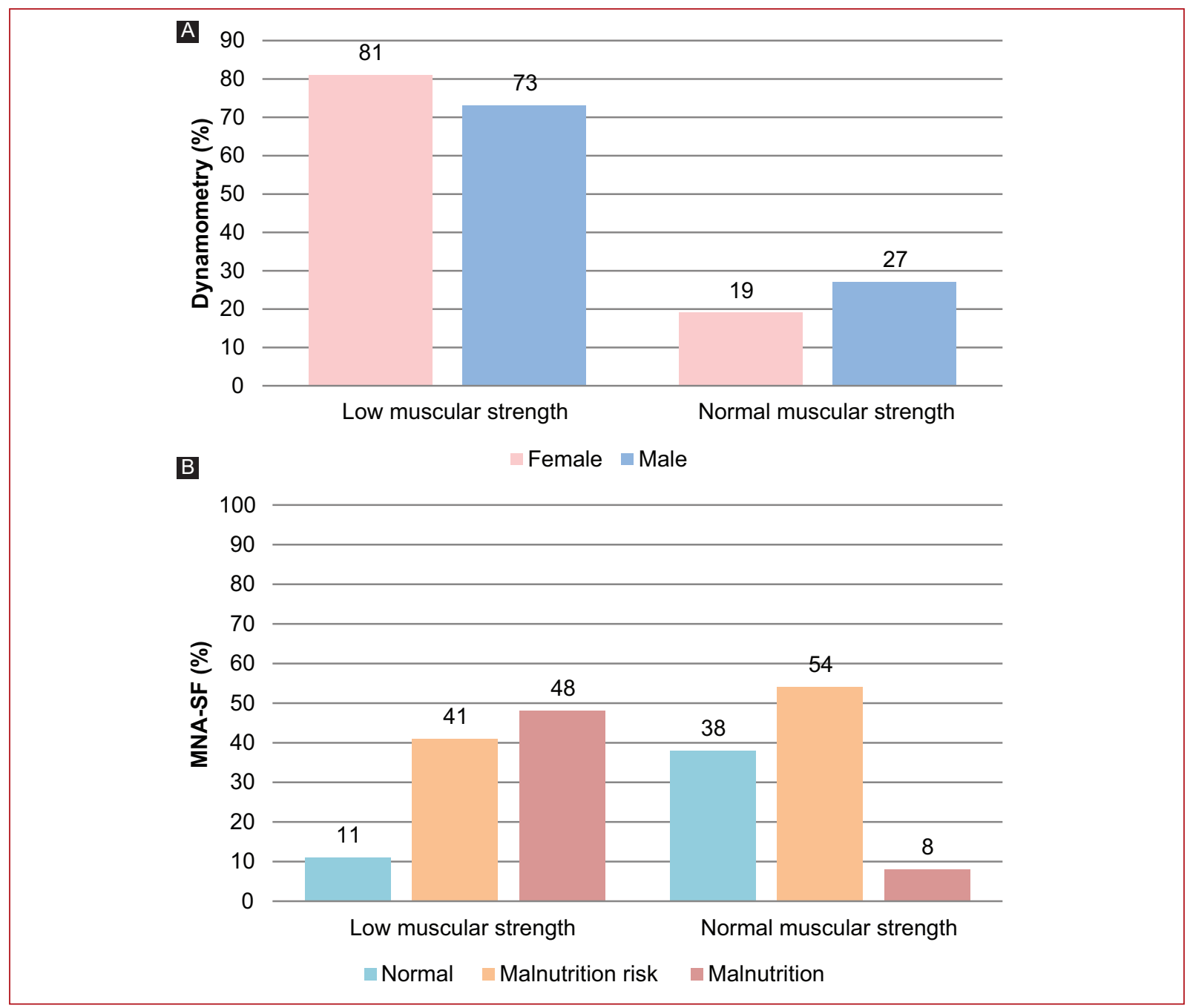

Figure 1. Dynamometry in the elderly at hospital admission. A: difference in muscle strength between genders.

B: difference in muscle strength and nutritional status (MNA-SF). MNA-SF: Mini Nutritional Assessment Short-Form.

presented a normal nutritional status, $55 \%$ stayed the same, while $45 \%$ were found with malnutrition at hospital discharge. There were no in-hospital deaths within this group.

No significant difference was observed between in-hospital mortality and malnutrition upon admittance $(p<0.052)$. Of the total registered deaths $(n=15), 40 \%$ presented a malnutrition risk and $60 \%$ presented malnutrition upon admittance.

\section{Discussion}

The prevalence of malnutrition in the elderly is very variable and depends on different factors such as the environment of the population in the elderly (institutionalized or hospitalized community), the use of different methods for the evaluation and diagnosis of malnutrition, as well as the heterogeneity of this population. The MNA-SF is a widely utilized tool to determine the risk of malnutrition or malnutrition in the elderly, in the hospital as well as in their social environment. In the present study, a high prevalence of malnutrition was found through the MNA-SF, in patients who are admitted to the hospital $(82 \%)$, which increased during their hospital stay.

On the other hand, a study conducted in the Colombian population showed that among the causes of hospitalization, the comorbidities significantly linked to a risk of malnutrition were cancer, HIV, and chronic renal diseases ${ }^{17}$. In the present research, the leading causes for hospitalization in those patients who presented malnutrition at the time of admittance determined by the 


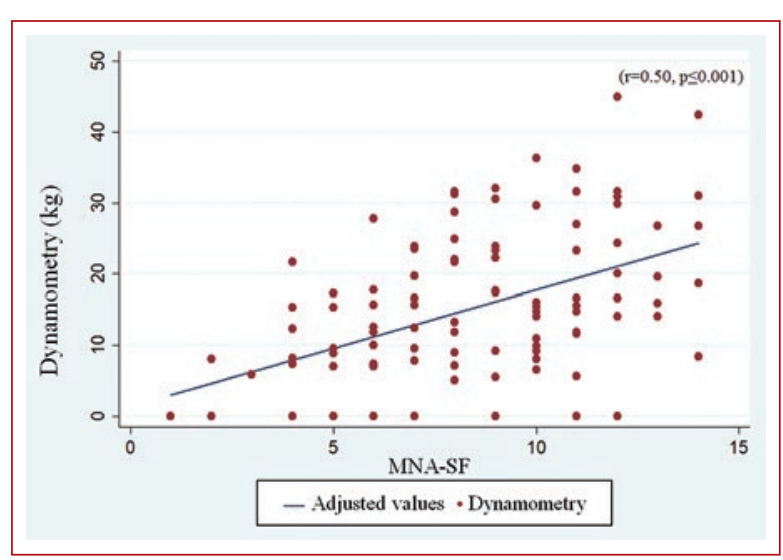

Figure 2. Pearson's correlation coefficient in muscle strength and nutritional status according to the MNA-SF $(r=0.50, p \leq 0.001)$. MNA-SF: Mini Nutritional Assessment Short-Form.

MNA-SF were malignant tumors (75\%) and the genitourinary system (59\%), while in those at risk of malnutrition, $55 \%$ had other causes and $54 \%$ had pathologies of the circulatory system.

Regarding muscle strength in the elderly, a study showed that handgrip strength measured by dynamometry is correlated as a predictor to show nutritional status according to the MNA-SF of the patient just like $\mathrm{BMI}$ or calf circumference ${ }^{18}$. In the present research, the nutritional status of the hospitalized elderly was evaluated using the MNA-SF and calf circumference, and a positive correlation was observed with handgrip strength $(r=0.50, p \leq 0.001)$.

Concerning calf circumference in this research, 61 patients presented a calf circumference of $<31 \mathrm{~cm}$ upon admission to the hospital, $81-9 \%$ remained the same at discharge, and $6.5 \%$ died. Other studies highlight the usefulness of this measure used as an indicator of nutritional status ${ }^{13,19}$ and mortality in the elderly ${ }^{20}$.

Concerning mortality, a study evaluated risk factors linked to hospitalized patients $>65$ years of age, showing a strong link between mortality and malnutrition according to the Malnutrition Universal Screening Tool and Short Nutritional Assessment Questionnaire ${ }^{21}$. The present study showed that of the total of in-hospital deaths registered $(n=15), 60 \%$ presented malnutrition and $40 \%$ presented a risk of malnutrition upon admission.

\section{Conclusions}

We can state that hospitalization plays a negative role not only in the percentage of patients older than
60 years of age at risk of malnutrition but also their muscle mass and strength, upon admission and discharge. A proper assessment of nutritional status upon hospital admission is fundamental for early detection of malnutrition, as well as to determine risk situations and identify the possible causes of nutritional deficit. This could help reduce the prevalence of in-hospital malnutrition, ensuring that the consequences of malnutrition by deficiency will not alter the course of their disease nor increase mortality rates.

\section{Conflicts of interest}

The authors declare that they have no conflicts of interest.

\section{Ethical disclosures}

Protection of human and animal subjects. The authors declare that no experiments were performed on humans or animals for this study.

Confidentiality of data. The authors declare that they have followed the protocols of their work center on the publication of patient data.

Right to privacy and informed consent. The authors have obtained the written informed consent of the patients or subjects mentioned in the article. The corresponding author is in possession of this document.

\section{References}

1. Alvarado-García AM, Salazar-Maya AM. Análisis del concepto de envejecimiento. Gerokomos. 2014;25:57-62.

2. Mujeres y Hombres en México 2018. Instituto Nacional de Estadística y Geografía-México. c2018. Available from: http://www.cedoc.inmujeres. gob.mx/documentos_download/MHM_2018.pdf.

3. Evans $C$, Malnutrition in the elderly: a multifactorial failure to thrive. Perm J. 2005:9:38-41.

4. Chapman IM. Nutritional disorders in the elderly. Med Clin North Am. 2006;90:887-907.

5. Ahmed T, Haboubi N. Assessment and management of nutrition in older people and its importance to health. Clin Interv Aging. 2010;5:207-16.

6. Rojanoi-Luque $X$, Sánchez-Ferrin $P$, Salvá A. Complicaciones de la hospitalización en personas mayores. Med Clin (Barc). 2016;146:550-4.

7. Ramos-Martínez A, Asensio-Vegas A, Núñez-Palomo S, Millán-Santos I. Prevalencia y factores asociados a malnutrición en ancianos hospitalizados. An Med Interna (Madrid). 2004;21:263-8.

8. Sánchez-López A, Moreno-Torres-Herrera R, Pérez de la Cruz A, Orduña-Espinosa R, Medina T, López-Martínez C. Prevalencia de desnutrición en pacientes ingresados en un hospital de rehabilitación y traumatología. Nutr Hosp. 2005;20:121-30.

9. Informe Mundial sobre el Envejecimiento y la Salud. Organización Mundial de la Salud. c2015. Available from: https://www.apps.who.int/iris/ bitstream/handle/10665/186466/9789240694873_spa.pdf;jsessionid=3C9BD60E734966792ECFDAE10BEA0E8E? sequence $=1$.

10. Kaiser MJ, Bauer JM, Rämsch C, Uter W, Guigoz Y, Cederholm T, et al. Frequency of malnutrition in older adults: a multinational perspective using the mini nutritional assessment. J Am Geriatr Soc. 2010;58:1734-8.

11. Rubenstein L, Harker J, Salvá A, Guigoz Y, Vellas B. Screening for undernutrition in geriatric practice: developing the short-form mini-nutritional assessment (MAN-SF). J Gerontol A Biol Sci Med Sci. 2001;56:366-72.

12. Miller E, Freund JE. Probabilidad y Estadística para Ingenieros. Mexico: Editorial Revertí Mexicana. 
13. Cuervo M, Ansorena D, García A, González-Martínez MA, Astiasarán I, Martínez JA. Valoración de la circunferencia de la pantorrilla como indicador de riesgo de desnutrición en personas mayores. Nutr Hosp. 2009;24:63-7.

14. Chatindiara I, Allen J, Popman A, Patel D, Richter M, Kruger M, et al. Dysphagia risk, low muscle strength and poor cognition predict malnutrition risk in older adults at hospital admission. BMC Geriatr. 2018;18:78.

15. Kaiser MJ, Bauer JM, Ramsch C, Uter W, Guigoz Y, Cederholm T, et al Validation of the mini nutritional assessment short-form (MNA-SF): a practical tool for identification of nutritional status. J Nutr Health Aging. 2009;13:782-8.

16. Clasificación Internacional de Enfermedades $10^{\circ}$. Organización Mundia de la Salud. c1994. Available from: https://www.sssalud.gob.ar/hospitales/archivos/cie_10_revi.pdf.

17. Cruz V, Bernal L, Buitrago G, Ruiz A. Screening for malnutrition among hospitalized patients in a Colombian University Hospital. Rev Med Chile. 2017;145:449-57.
18. Kizilarslanoglu MC, Kilic MK, Gokce D, Sakalar T, Ulger Z. Is it possible using handgrip strength instead of body mass index in MNA-SF test to assess the nutritional status of geriatric patients? J Nutr Health Aging. 2017;21:579-84.

19. Portero-McLellan KC, Staudt C, Silva FR, Delbue-Bernardi JL, Baston-Frenhani P, Leandro-Mehri VA. The use of calf circumference measurement as an anthropometric tool to monitor nutritional status in elderly inpatients. J Nutr Health Aging. 2010;14:266-70.

20. Wijnhoven HA, van Bokhorst-de van der Schueren MA, Heymans MW, de Vet HC, Kruizenga HM, Twisk JW, et al. Low mid-upper arm circumference, calf circumference, and body mass index and mortality in older persons. J Gerontol A Biol Sci Med Sci. 2010;65: 1107-14.

21. Leiva-Badosa E, Badia-Tahull M, Casas NV, Sangrador GE, Méndez CF, et al. Hospital malnutrition screening at admission: malnutrition increases mortality and length of stay. Nutr Hosp. 2017;34:907-13. 